\title{
Class Association Rule Pada Metode Associative Classification
}

\author{
E. Karyawati dan E. Winarko
}

\begin{abstract}
Frequent patterns (itemsets) discovery is an important problem in associative classification rule mining. Differents approaches have been proposed such as the Apriori-like, Frequent Pattern (FP)-growth, and Transaction Data Location (Tid)list Intersection algorithm. This paper focuses on surveying and comparing the state of the art associative classification techniques with regards to the rule generation phase of associative classification algorithms. This phase includes frequent itemsets discovery and rules mining/extracting methods to generate the set of class association rules (CARs). There are some techniques proposed to improve the rule generation method. A technique by utilizing the concepts of discriminative power of itemsets can reduce the size of frequent itemset. It can prune the useless frequent itemsets. The closed frequent itemset concept can be utilized to compress the rules to be compact rules. This technique may reduce the size of generated rules. Other technique is in determining the support threshold value of the itemset. Specifying not single but multiple support threshold values with regard to the class label frequencies can give more appropriate support threshold value. This technique may generate more accurate rules. Alternative technique to generate rule is utilizing the vertical layout to represent dataset. This method is very effective because it only needs one scan over dataset, compare with other techniques that need multiple scan over dataset. However, one problem with these approaches is that the initial set of tid-lists may be too large to fit into main memory. It requires more sophisticated techniques to compress the tid-lists.
\end{abstract}

Kata Kunci-frequent itemset, CAR, apriori, FP-growth, tid-list, associative classification

Eka Karyawati, Jurusan Ilmu Komputer, Fakultas matematika dan Ilmu Pengetahuan Alam, Universitas Gadjah Mada. e-mail: ekakaryawati@yahoo.com

Edi Winarko, Jurusan Ilmu Komputer, Fakultas matematika dan Ilmu Pengetahuan Alam, Universitas Gadjah Mada. e-mail: ewinarko@yahoo.com

\section{PENDAHULUAN}

A ssociative classification (AC) adalah cabang dalam data mining yang memanfaatkan metode association rule discovery dalam masalah klasifikasi. Beberapa studi memberikan bukti bahwa teknik AC dapat memberikan model klasifikasi yang lebih akurat dibandingkan dengan teknik-teknik klasifikasi tradisional seperti decision tree, rule induction, dan pendekatan probalistik [12].

Sama seperti association rule mining, masalah mendasar pada AC adalah metode dalam membangkitkan frequent itemset dari data yang berukuran besar. Tugas ini memakan waktu yang sangat besar karena data transaksi harus discan berulang kali untuk mencari frequent itemset. Banyak riset mengusulkan teknik-teknik untuk memperbaiki metode dalam membangkitkan frequent itemset. Membangkitkan frequent itemset merupakan satu bagian dari fase pertama dalam metode $\mathrm{AC}$, yang disebut fase rule generation. Fase rule generation meliputi metode untuk menemukan frequent itemset dan metode untuk mengekstrak rule dengan tujuan membangkitkan himpuan class association rule (CAR). Fase kedua pada metode AC adalah fase building classifier dan fase klasifikasi. Fase building classifier mencoba menghilangkan redundant rule (pruning) dan mengurutkan rule yang berguna (useful) dalam urutan yang tepat (ranking). Fase klasifikasi adalah fase untuk memprediksi atau mengklasifikasikan data yang belum dikategorikan dalam kelas tertentu atau belum berlabel.

Paper ini difokuskan pada survey dan pembandingan metode associative classification dengan fokus pada fase pertama dari algoritma associative classification.

Ada banyak metode associative classification mining seperti CBA, CMAR, MCAR, L3G, dan sebagainya. Metode-metode tersebut secara umum menggunakan beberapa pendekatan berbeda dalam pembangkitan rule (CAR). Penulis membandingkan tiga jenis pendekatan yang berbeda: metode Apriori, metode Frequent 
Pattern (FP)-Growth Tree, dan metode Transaction Data Location (Tid)-list Intersection.

\section{METODE PENELITIAN}

Metode penelitian yag digunakan adalah studi literatur dengan mereview beberapa jurnal yang terkait dengan metode associative classification, khususnya pada fase rule generation.

Penulis membandingkan tiga jenis pendekatan yang berbeda: metode Apriori, metode Frequent Pattern (FP)-Growth Tree, dan metode Transaction Data Location (Tid)-list Intersection.

\subsection{Associative Classification}

Associative classification adalah kasus khusus dari association rule mining dimana hanya atribut kelas yang digunakan sebagai sisi kanan rule, sebagai contoh, $X \rightarrow Y, Y$ harus merupakan atribut kelas [7].

Misalkan dataset training $D$ mempunyai $m$ atribut/item berbeda, $I=\left\{i_{1}, i_{2}, \ldots, i_{m}\right\}$ dan $C$ adalah daftar dari label kelas. Banyaknya baris dalam $D$ dinotasikan sebagai $|D|$. Atribut dapat bertipe kategorik atau kontinu. Pada kasus atribut bertipe kategorik, semua kemungkinan nilai dipetakan ke himpunan bilangan integer positif. Untuk atribut yang kontinu, atribut ini harus dideskritisasi untuk diubah ke bentuk kategorik.

Dalam masalah associative classification, setiap transaksi mengandung subset dari itemitem yang dipilih dari $I\left(d_{i}\right)$ dan label kelas $c$. Kumpulan dari nol atau lebih item disebut itemset. Itemset yang terdiri dari $k$ item disebut $k$-itemset. Sebuah transaksi dikatakan mengandung itemset $X$ jika $X$ adalah subset dari $d_{j}\left(X \subseteq d_{i}\right)$.

Rule $X \rightarrow c$ pada $D$ mempunyai condition support $\alpha$ jika $\alpha \%$ kasus pada $D$ mengandung $X$. Rule $X \rightarrow c$ mempunyai rule support $\beta$ jika $\beta \%$ kasus mengandung $X$ dan dilabelkan dengan kelas $c$. Selanjutnya, rule $X \rightarrow c$ mempunyai nilai confidence $\delta$ jika $\delta \%$ kasus pada $D$ yang mengandung $X$ dilabelkan dengan kelas $c$.

Itemset disebut frequent itemset jika nilai support dari itemset tersebut melampaui nilai minimum support (minsupp) threshold. Rule $r$ disebut frequent rule jika nilai rule support dari $r$ melewati nilai minsupp threshold. Sebuah rule diekstrak sebagai Class Association Rules (CAR) jika nilai support dan confidence dari $r$ melewati nilai minsupp and minimum confidence (minconf) threshold.

\subsection{Metode Apriori}

Metode AC pertama yang menggunakan algoritma Apriori adalah metode CBA [7]. Prinsip Apriori menyatakan bahwa jika sebuah itemset adalah frequent, maka semua subsetnya juga frequent [1].

Misalkan $F k$ menotasikan himpunan frequent $k$-itemset. Misalkan juga $C k$ adalah himpunan $k$-itemset. Algoritma CAR generation dari metode CBA dapat dilihat pada Gambar 1.

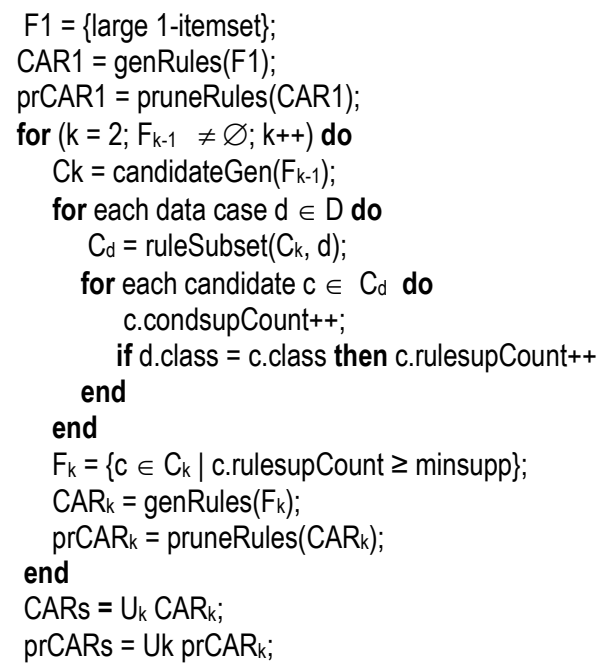

Gambar 1. Algoritma Rule Generation CBA.

Sebagai ilustrasi dari algoritma CBA, perhatikan contoh dataset training pada Tabel 1. Misalkan diberikan nilai minsupp threshold 25\% dan nilai minconf threshold $25 \%$.

Tabel 1. Training Dataset

\begin{tabular}{|l|l|l|}
\hline TID & Set of Items & Class Label \\
\hline 1 & a, b, c & B \\
\hline 2 & a, b, c, d & B \\
\hline 3 & a, b, c & B \\
\hline 4 & a, b, d & B \\
\hline 5 & c, d & A \\
\hline 6 & b, c & A \\
\hline 7 & a, b, c & B \\
\hline 8 & a, b, c & B \\
\hline
\end{tabular}


Pertama-tama dataset discan untuk memperoleh himpunan frequent 1-itemset $(F 1)$. Setelah itu nilai confidence dari $F 1$ dihitung. F1 yang mempunyai nilai confidence lebih besar atau sama dengan nilai minconf threshold dibangkitkan sebagai CAR 1-itemset. Item yang dibangkitkan sebagai $\mathrm{F} 1$ adalah $(\mathrm{a}, \mathrm{B}),(\mathrm{B}, \mathrm{B}),(\mathrm{c}$, B), (c, A), dan (d, B).

Selanjutnya, F1 digunakan untuk membangkitkan kandidat 2-itemset (C2), dengan menggabungkan dua elemen F1. Dataset discan lagi untuk memeriksa apakah nilai rule support dari $C 2$ memenuhi nilai minsupp threshold. Jika memenuhi, maka $C 2$ akan dibangkitkan sebagai frequent 2-itemset ( $F 2)$. $\quad F 2$ yang mempunyai nilai confidence memenuhi minconf threshold akan diekstrak sebagai CAR 2-itemset.

Metode AC yang lain adalah metode MsCBA [8]. MsCBA memperbaiki algoritma Apriori dengan menggunakan nilai minsupp threshold lebih dari satu (multiple class minimum support, minsups). Metode ini menentukan minsups dengan memberikan nilai minsupp threshold yang berbeda pada setiap kelas tergantung dari frekwensi kelas tersebut.

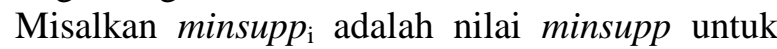
kelas $c_{\mathrm{i}}$ dan sebuah nilai global minsupp, g_minsupp diberikan oleh user, maka: minsupp $_{i}=g \_$minsupp $*$ freqClass $\left(c_{i}\right)$.

Metode LC adalah metode AC yang juga memperbaiki metode CBA [13]. Metode LC memperhatikan label kelas dari frequent itemset sebelum dilakukan penggabungan pada proses pembangkitan kandidat itemset. Hal ini berbeda dengan metode CBA yang tidak memperhatikan label kelas. Sebagai contoh, jika $A$ dan $B$ adalah dua frequent itemset yang pada iterasi $\mathrm{k}$, maka LC akan menggabungkan $A$ dan $B$ menjadi kandidat $(k+1)$-itemset jika $A$ dan $B$ mempunyai label kelas yang sama.

\subsection{Metode FP-Growth Tree}

Metode FP-Growth Tree adalah metode untuk membangkitkan frequent itemset tanpa membangkitkan kandidat itemset seperti pada metode Apriori [5]. Metode ini menggunakan struktur data padat (compact) yang disebut FPtree dan mengekstrak frequent itemset secara langsung dari struktur ini.

FP-tree dibentuk hanya dengan melakukan dua kali scanning pada dataset. Scanning yang pertama untuk memperoleh himpunan frequent item kemudian mengurutkan item sesuai nilai supportnya dan scanning yang kedua untuk mengkonstruksi FP-tree.

FP-growth adalah algoritma yang membangkitkan frequent itemset dari FP-tree dengan menelusuri FP-tree secara bottom-up. Algoritma ini menggunakan strategi divide-andconquer dalam memilah masalah menjadi lebih kecil dengan mengkonstruksi conditional FP-tree dari global FP-tree [5].

Salah satu teknik AC yang menggunakan algoritma FP-growth tree adalah metode CMAR [6]. CMAR menscan dataset training $D$ untuk memperoleh frequent 1-itemset $(F)$. Kemudian, CMAR mengurutkan item dalam $F$ sesuai nilai supportnya secara menurun, himpunan ini disebut $F$-list. Untuk setiap himpunan item (set of items, $d_{i}$ ) dalam dataset training, item yang muncul dalam $F$-list diekstrak dan diurutkan sesuai F-list.

Tabel 2. Training Dataset sesuai F-list

\begin{tabular}{|l|l|l|}
\hline TID & Set of Items & Class Label \\
\hline 1 & c, b, a & B \\
\hline 2 & c, b, a, d & B \\
\hline 3 & c, b, a & B \\
\hline 4 & b, a, d & B \\
\hline 5 & c, d & A \\
\hline 6 & c, b & A \\
\hline 7 & c, b, a & B \\
\hline 8 & c, b, a & B \\
\hline
\end{tabular}

Sebagai contoh, perhatikan dataset pada Tabel 1. Tabel 1 memperlihatkan dataset dengan 8 transaksi. Misal diberikan nilai minsupp threshold $25 \%$ dan nilai minconf threshold 25\% Maka, F-list $=c-b-a-d$. Daftar dataset yang sesuai dengan F-list disajikan dalam Tabel 2.

Himpunan item yang pertama $\{c, b, a\}$ diekstrak dan disisipkan pada FP-tree sebagai cabang yang paling kiri. Label kelas dicantumkan pada node yang terakhir pada path tersebut.

Himpunan item yang kedua mempunyai prefiks yang sama dan dua item yang sama dengan dengan transaksi yang pertama. Sehingga, path untuk transaksi yang kedua overlap dengan path yang pertama. Frekwensi node-node yang bersesuaian dinaikkan. Hasil FP-tree bisa dilihat pada Gambar 2. 


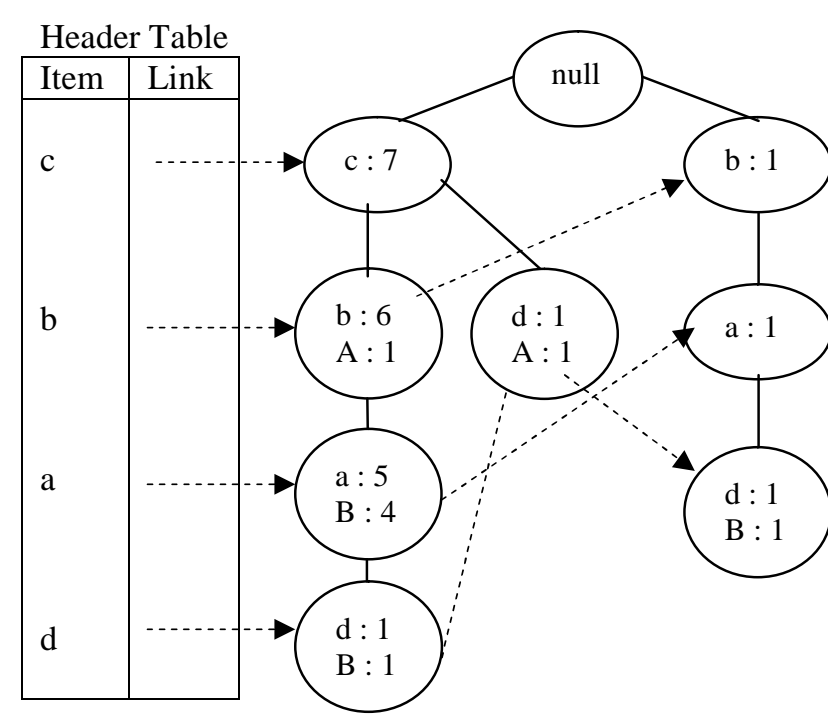

Gambar 2. The Global FP-tree

Berdasarkan F-list, CMAR membagi himpunan CAR kedalam 4 subset tanpa overlap: (1) himpunan yang mempunyai $d$, (2) mempunyai $a$ tetapi tidak ada $d$, (3) mempunyai $b$ tetapi tidak ada $a$ atau $d$, dan (4) hanya mempunyai $c$.

Untuk menemukan subset rule yang mempunyai item $d$, CMAR menelusuri path yang mempunyai node $d$ dan melihat "ke atas" untuk mengumpulkan $d$-projected dataset. Selanjutnya CMAR melakukan penambangan (mining) secara rekursif pada conditional FP-tree, dan memperoleh itemset $a d, b d, c d$, dan bad. Berdasarkan informasi distribusi label kelas, CMAR membangkitkan CAR: $\mathrm{d} \rightarrow \mathrm{B}$, ad $\rightarrow \mathrm{B}$, bd $\rightarrow$ B, dan BAD $\rightarrow$ B.

Metode lain yang menggunakan algoritma FP-growth tree adalah metode L3G [3]. Metode L3G mengkodekan rule yang lengkap menggunakan rule yang compact dengan memanfaatkan konsep closed itemset dan essential rule [2]. Algoritma FP-growth tree diadopsi untuk mengekstrak rule dari bentuk compact tersebut. Algoritma L3G dapat dilihat pada Gambar 3.

Sebagai ilustrasi dari algoritma L3G, perhatikan contoh dataset pada Tabel 1. Misal diberikan nilai minsupp threshold $=25 \%$ dan nilai minconf threshold $=25 \%$. Dataset yang telah terurut disajikan pada Tabel 2. Pertamatama dataset diproyeksikan terhadap item $d$, maka $G=d$ (lihat Gambar 4). Karena tidak ada item yang tercakup pada semua transaksi pada $D_{d}, T=\varnothing$. Kedua label kelas $B$ dan $A$ ada pada $D_{d}$, sehingga dua compact rule dapat diekstrak., $\{G=d, T=\varnothing\} \rightarrow B$ and $\{G=d, T=\varnothing\} \rightarrow A$.
Masing-masing compact rule mengkodekan satu rule (lihat Gambar 4).

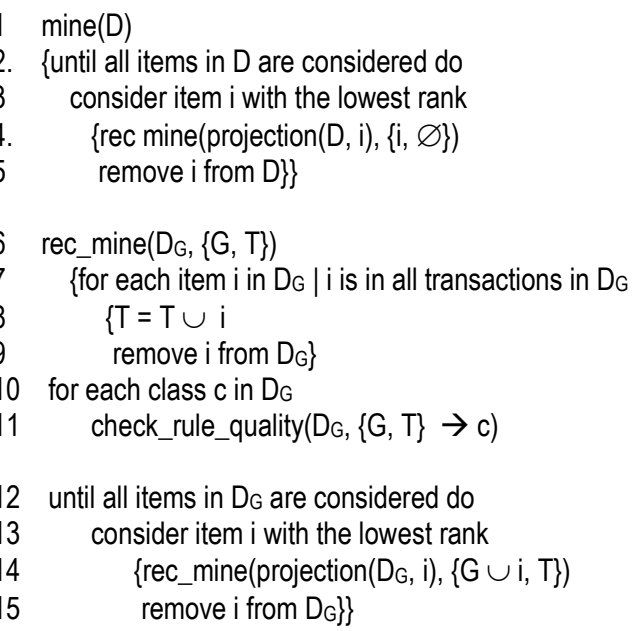

Gambar 3. Algoritma L3G Rule Extraction

\begin{tabular}{|l|l|l|}
\hline \multicolumn{3}{|c|}{$\mathrm{D}_{\mathrm{d}}$} \\
\hline Tid & Items & Class Label \\
\hline 2 & c, b, a & B \\
\hline 4 & b, a & B \\
\hline 5 & c & A \\
\hline
\end{tabular}

\begin{tabular}{|l|l|l|l|}
\hline Compact Rule & Rule & $\begin{array}{l}\text { Sup } \\
\%\end{array}$ & $\begin{array}{l}\text { Conf } \\
\%\end{array}$ \\
\hline$\{\mathrm{G}=\mathrm{d}, \mathrm{T}=\varnothing\} \rightarrow \mathrm{B}$ & $\mathrm{d} \rightarrow \mathrm{B}$ & 25 & 66.67 \\
\hline$\{\mathrm{G}=\mathrm{d}, \mathrm{T}=\varnothing\} \rightarrow \mathrm{A}$ & $\begin{array}{l}\mathrm{d} \rightarrow \mathrm{A} \\
\text { It is not } \\
\text { CAR }\end{array}$ & 12.5 & 33.33 \\
\hline
\end{tabular}

Gambar 4. Projected Dataset $D_{d}$ dan Compact

Rule

$D_{\text {d }}$ selanjutnya dapat diproyeksikan terhadap item $a, \mathrm{~b}$, dan c, sehingga menghasilkan projected dataset $D_{\mathrm{da}}(G=d a), D_{\mathrm{db}}(G=d b)$, dan $D_{\mathrm{dc}}(G=d c)$. Proses yang dilakukan untuk menghasilkan compact rule sama seperti ilustrasi diatas.

Metode AC yang lain adalah metode DPPMine [4]. Metode ini memodifikasi algoritma $\mathrm{FP}$-growth tree dengan mencari secara langsung itemset yang mempunyai nilai diskrimintif tinggi dengan menggunakan metode branch-and-bound-search.

Dataset ditransformasikan ke bentuk FP-tree dan selanjutnya itemset yang diskriminatif dicari secara langsung.

Theori upper bound digunakan dalam metode pencarian branch-and-bound ini. Nilai upper bound yang digunakan pada metode ini adalah nilai information gain. Formula 
information gain dan information gain upper bound disajikan pada [4].

Ide dasar dari metode DPPMine adalah, selama proses rekursi penambangan (mining) pada FP-growth, sebuah peubah global digunakan untuk menyimpan itemset yang paling diskriminatif yang telah ditemukan dan nilai information gainnya. Nilai upper bound dari information gain dari ukuran conditional dataset dihitung, sebelum mengkonstruksi conditional FP-tree.

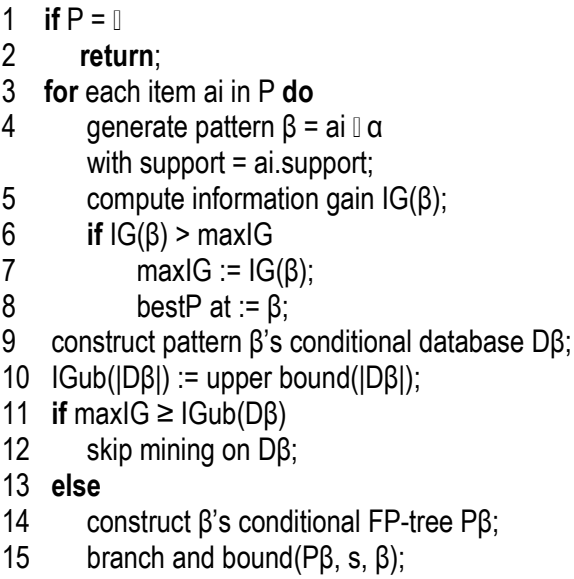

Gambar 5. Algoritma Branch-and-Bound Mining

Gambar 5 memperlihatkan algoritma branch-and-bound mining. $I G(\beta)$ pada baris 6 adalah information gain dari frequent itemset $\beta$ dan $\operatorname{IGub}(|D \beta|)$ pada baris 10 adalah information gain upper bound yang diberikan oleh conditional dataset $D \beta$.

Untuk mengilustrasikan metode ini, perhatikan contoh pada Tabel 2. Misal diberikan nilai minsupp threshold 25\% . Global FP-tree diperlihatkan pada Gambar 2.

Frequent itemset yang pertama dibangkitkan adalah item $d$ dengan nilai $I G(d)=$ 0.016. Maka maxIG adalah 0.016. Conditional dataset $\mathrm{D}_{\mathrm{d}}$ disajikan pada Gambar 4 dengan ukuran conditional dataset adalah 3 , nilai information gain upper boundnya adalah $I G_{u b}(3)$ $=0.467$. Karena $I G_{u b}(3)>\max I G$, conditional FP-tree terhadap $d$ akan diekstrak untuk memperoleh itemset yang diskriminatif. Mining secara rekursif pada conditional FP-tree menghasilkan itemset $a d, b d, c d$ dan $b a d$, dengan $I G(a d)=0.123, I G(b d)=0.123, I G(c d)=0.074$ and $I G(b a d)=0.123$.
Dengan cara yang sama seperti ilustrasi diatas diperoleh bahwa penambangan (mining) rule pada conditional FP-tree terhadap a tidak perlu dilakukan (bisa dilewatkan).

\subsection{Metode Tid-List Intersection}

Secara umum, terdapat dua representasi dataset yaitu layout horisontal [1] and vertikal [14]. Tabel 3 adalah contoh layout horisontal. Dalam pencarian frequent itemsets pada layout horisontal dataset discan secara berulang. Scanning dilakukan untuk menghitung nilai support dan melakukan pencocokan itemset.

Pada layout vertikal, dataset memuat sebuah group item dimana masing-masing item diikuti oleh tid-list [9], seperti terlihat pada Tabel 4, yang merupakan representasi vertikal dari Tabel 3. Tid dari sebuah itemset adalah lokasi transaksi pada dataset yang mengandung itemset tersebut.

Tabel 3. Training Dataset

\begin{tabular}{|l|l|l|}
\hline TID & Set of Items & Class Label \\
\hline 1 & a, b, e & A \\
\hline 2 & b, c, d & B \\
\hline 3 & c, e & B \\
\hline 4 & c, d, e & B \\
\hline 5 & a, b, c, d, f & A \\
\hline 6 & c, e & B \\
\hline 7 & a, b & A \\
\hline 8 & a, b, c & A \\
\hline
\end{tabular}

Tabel 4. Representasi Vertikal dari Dataset

\begin{tabular}{|c|c|c|c|c|c|c|}
\hline \multicolumn{5}{|c|}{ Itemset } & \multicolumn{2}{|c|}{ Class Label } \\
\hline $\mathrm{a}$ & b & $\mathrm{c}$ & $\mathrm{d}$ & e & $\bar{A}$ & $\mathrm{~B}$ \\
\hline 1 & 1 & 2 & 2 & 1 & 1 & 2 \\
\hline 5 & 2 & 3 & 4 & 3 & 5 & 3 \\
\hline 7 & 5 & 4 & 5 & 4 & 7 & 4 \\
\hline 8 & 7 & 5 & & 6 & 8 & 6 \\
\hline & 8 & 6 & & & & \\
\hline & & 8 & & & & \\
\hline
\end{tabular}

Salah satu metode AC yang menggunakan algoritma tid-list intersection adalah metode MCAR [11]. Metode ini menscan satu kali dataset training untuk memperoleh frequent item. Frequent item ini akan disimpan dengan lokasi transaksinya ( $t i d)$ pada sebuah array. Frequent $k$ itemset diperoleh dengan mengiriskan tid-list dari frequent itemset yang sudah ditemukan. Tid-list dari frequent single itemset juga digunakan untuk 
menghitung nilai support and confidence dari rule $k$-itemset.

Sebagai ilustrasi dari metode CMAR, perhatikan contoh dataset pada Tabel 3. Misal diberikan nilai minsupp threshold $25 \%$ dan nilai minconf threshold 50\%. Setelah scanning dataset, diperoleh bahwa nilai support dari item $f$ tidak memenuhi nilai minsupp threshold, maka item $f$ dihilangkan. Item yang lain beserta tid-nya disimpan secara vertikal seperti terlihat pada Tabel 4.

Tid-list dua item $F 1$ diiriskan untuk membangkitkan frequent 2-itemset (F2). Contoh, perhatikan item $a$ dan $b$ pada Tabel 4 . Hasil irisan dari tid-listnya adalah $\{1,5,7,8\}$. Ini adalah representasi dari tid-list itemset $a b$. Maka nilai condition support itemset $a b$ adalah $4 / 8 *$ $100 \%=50 \%$.

Tid-list itemset $a b$ dapat digunakan untuk menghitung nilai rule support dengan mengiriskan tid-list itemset $a b$ dan setiap tid-list label kelas. Hasil pengirisan antara tid-list itemset $a b$ dan label kelas $A$ adalah $\{1,5,7,8\}$ dan label kelas $B$ adalah $\varnothing$. Sehingga, tidak ada rule $a b \rightarrow B$ dan terdapat empat rule $a b \rightarrow A$. Nilai rule support $a b \rightarrow A$ adalah $4 / 8 * 100 \%=$ $50 \%$ dengan nilai confidence $4 / 4 * 100 \%=$ $100 \%$. Rule ini dibangkitkan sebagai $F 2$ dan sebagai CAR 2-itemset. Kandidat frequent 2itemset yang lain (itemset $a c, a d, a e, b c, b d, b e$, $c d, c e$, dan $d e$ ) dapat dibangkitkan dengan cara yang sama.

Metode CMAR diperbaiki dengan diusulkannya metode baru yang disebut metode CACA [10]. CACA memodifikasi algoritma tidlist intersection dengan mengecilkan jumlah kombinasi item yang diperlukan. Ide dasar dari metode CACA adalah membagi himpunan item ke dalam $k$ himpunan yang lebih kecil sesuai label kelas.

Perhatikan item $a$ dan label kelas $A$. hasil irisan antara tid-list mereka adalah $\{1,5,7,8\}$. Nilai rule support $a \rightarrow A$ memenuhi nilai minsupp threshold. Item a dimasukkan ke himpunan itemset label kelas $A$, dinotasikan $C 1$. Perhatikan item $c$ dan label kelas $B$. Hasil irisan dari tid-list mereka adalah $\{2,3,4,6\}$. Nilai rule support $c \rightarrow B$ memenuhi nilai minsupp threshold. Item $c$ dimasukkan ke himpunan itemset label kelas $B$, dinotasikan $C 2$.

Irisan antara setiap tid-list item dan setiap label kelas menghasilkan dua himpunan itemset $C 1=\{a, b, c\}$ dan $C 2=\{c, d, e\}$. Element $C 1$ dan $C 2$ adalah frequent 1 -itemsets $(F 1)$.
Frequent 2-itemset atau lebih dapat dilakukan dengan memperhatikan kombinasi dari elemen $C 1$ (untuk rule dengan label kelas $A$ ) dan kombinasi elemen $C 2$ (untuk rule dengan label kelas B). Perhatikan himpunan $C l=\{a, b, c\}$, maka rule yang mungkin adalah $a b \rightarrow A, a c \rightarrow A$, dan $b c \rightarrow A$. Dari himpunan $C 2=\{c, d, e\}$, rule yang mungkin adalah $c d \rightarrow B, c e \rightarrow B$, dan $d e \rightarrow$ $B$. Nlai rule support dapat dihitung hanya dengan mengiriskan antara tid-list 2-itemset dan tid-list label kelasnya (contoh, antara tid-list $a b$ dan label kelas $A$ ).

\section{HASIL DAN PEMBAHASAN}

Masalah yang paling penting pada fase rule generation adalah metode dalam menemukan frequent itemset. Algoritma Apriori adalah algoritma yang sering digunakan pada metode associative classification untuk menemukan frequent itemset. Algoritma ini membangkitkan kandidat $(k+1)$-itemset dengan menggabungkan dua frequent $k$-itemset. Semua subset dari sebuah itemset harus dibangkitkan, walaupun tidak semua frequent itemset berguna. Hal ini menyebabkan terdapat dua masalah utama pada algoritma ini: (1) pembangkitan kandidat itemset dalam jumlah yang sangat besar, dan (2) terjadi pengulangan scanning ke dataset dan pengecekan kandidat dengan pencocokan itemset.

Masalah ini diperbaiki oleh Han, et. al., (2004) dengan mengajukan algoritma baru yang disebut metode FP-growth. FP-growth membangkitkan frequent itemset tanpa melakukan pembangkitan kandidat itemset. Pada metode ini, stuktur data yang disebut FP-tree digunakan untuk menyimpan informasi frekwensi dari itemset dalam bentuk yang dimampatkan (compact rule). Metode ini hanya memerlukan dua kali scanning ke dataset, sehingga metode FP-growth jauh lebih cepat daripada metode Apriori.

Masalah yang masih dihadapi pada metode FP-growth adalah jumlah frequent itemset dan rule yang dibangkitkan masih cukup besar. Salah satu teknik yang digunakan untuk mengurangi jumlah frequent itemset adalah dengan memanfaatkan konsep nilai information gain dari itemset sehingga hanya itemset yang diskriminatif yang dibangkitkan [4].

Jumlah rule yang dibangkitkan dapat dikurangi dengan memampatkan bentuk rule (compact rule). Pemampatan bentuk rule, dapat dilakukan dengan menggunakan konsep essential 
rule dengan memanfaatkan konsep closed frequent itemset.

Teknik lain yang digunakan untuk memperbaiki metode dalam membangkitkan frequent itemset adalah dengan memanfaatkan representasi dataset secara vertikal. Keuntungan utama pada teknik ini adalah nilai support dari itemset dihitung dengan mengiriskan tid-list dari itemset [9, 14]. Metode ini hanya memerlukan satu kali scanning ke dataset untuk menentukan frequent 1-itemset. Masalah yang dihadapi pada metode ini adalah ukuran awal dari tid-list kemungkinan terlalu besar agar bisa dimuat pada memori utama. Sehingga memerlukan teknik yang efektif untuk memampatkan ukuran tid-list.

Masalah lain dalam pembangkitan class association rule adalah penentuan nilai minimum support threshold. Kebanyakan teknik AC hanya menggunakan satu nilai minimum support threshold yang ditentukan oleh user. Cara penentuan nilai minsupp threshold ini kurang efektif terutama pada dataset transaksi dengan frekwensi kelas yang tidak seimbang. Teknik yang digunakan untuk memperbaiki kondisi ini adalah menentukan nilai minsupp threshold lebih dari satu dengan memperhatikan frekwensi label kelas dari data transaksi [8].

\section{KESIMPULAN}

Masalah utama yang dihadapi dalam membangkitkan class association rule pada metode associative classification adalah bagaimana membentuk algoritma yang efektif untuk menemukan frequent itemset. Beberapa teknik yang diusulkan oleh peneliti difokuskan pada pengurangan jumlah frequent itemset dan rule yang dibangkitkan. Frequent itemset set yang dibangkitkan seharusnya yang berguna (diskriminatif). Disamping itu, jumlah rule yang sangat besar seharusnya bisa dimampatkan sehingga tidak terlalu banyak menghabiskan ruang penyimpanan.

Fokus lain dari para peneliti adalah teknik dalam menentukan nilai minimum support threshold. Penentuan nilai minsupp threshold sangat mempengaruhi keakuratan rule yang dihasilkan.

Teknik lain pada metode AC terutama pada fase rule generation adalah pemanfaatan layout vertikal dari representasi dataset. Teknik ini sangat efektif karena hanya memerlukan satu kali scanning ke dataset transaksi dibandingkan dengan metode Apriori yang memerlukan perulangan scanning ke dataset.

\section{SARAN}

Teknik yang cukup menarik pada fase rule generation dari metode associative classification adalah pemanfaatan layout vertikal dari representasi dataset. Teknik ini sangat efektif karena hanya memerlukan satu kali scanning ke dataset transaksi. Salah satu kendala yang dihadapi pada pemanfaatan layout vertikal dari dataset adalah ukuran tid-list dari itemset yang sangat besar. Untuk mengatasi masalah ini, diperlukan pengkajian lebih lanjut tentang metode yang efektif untuk memampatkan ukuran tid-list dari itemset.

\section{DAFTAR PUSTAKA}

[1] Agrawal, R. \& Srikant, R., 1994, Fast Algorithms for Mining Association Rule, In Proceedings of the 20th International Conference on Very Large Data Base, Morgan Kaufmann, Santiago, Chile, September 12-15.

[2] Baralis, E. \& Chiosano, S., 2004, Essential Classification Rule Sets, Journal of ACM Transactions on Database Systems, vol. 29, no. 4, pp. 635-674

[3] Baralis, E., Chiusano, S. \& Graza, P. 2004b, On Support Thresholds in Associative Classification, In Proceedings of the 2004 ACM Symposium on Applied Computin, Nicosia, Cyprus, March $14-17$.

[4] Cheng, H., Yan, X., Han, J. \& Yu, P.S., 2008, Direct Discriminative Pattern Mining for Effective Classification, In Proceedings of the $24^{\text {th }}$ IEEE International Conference on Data Engineering, Cancún, México, April 7-12.

[5] Han, J., Pei, J., Yin, Y. \& Mao, R., 2004, Mining Frequent Patterns without Candidate Generation: A Frequent Pattern Tree Approach, Journal of Data Mining and Knowledge Discovery, vol. 8, pp. 53-87

[6] Li, W., Han, J. \& Pei, J., 2001, CMAR: Accurate and Efficient Classification Based on Multiple-Class Association Rule, In Proceedings of the International Conference on Data Mining (ICDM'01), San Jose, CA, November 29 - December

[7] Liu, B., Hsu, W. \& Ma, Y., 1998, Integrating Classification and Association Rule Mining, In Proceedings of the International Conference on Knowledge Discovery and Data Mining, New York, August 27 - 31.

[8] Liu, B., Ma, Y. \& Wong, C.K., 2000, Improving an Association Rule Based Classifier, In Proceedings of the $4^{\text {th }}$ European Conference on Principles of Data Mining and Knowledge Discovery, Lyon, France, September 13-16.

[9] Savasere, A., Omiecinski, E. \& Navathe, S., 1995, An Efficient Algorithm for Mining Association Rules in Large Databases, In Proceedings of the 21st conference on Very Large Databases (VLDB'95), Zurich,Switzerland, September 11-15. 
[10] Tang, Z. \& Liao, Q., 2007, A New Class Based Associative Classification Algorithm, IAENG International Journal of Applied Mathematics, vol. 36: 2.

[11] Thabtah, F., Cowling, P. \& Peng, Y., 2005, MCAR: MultiClass Classification Based on Association Rule Approach, In Proceeding of the 3rd IEEE International Conference on Computer Systems and Applications, Cairo, Egypt, January 36.

[12] Thabtah, F., 2007, A Review of Associative Classification Mining, Journal of The Knowledge Engineering Review, vol. 22:1, pp. 37-65.

[13] Thabtah, F., Mahmood, Q. \& McCluskey, L., 2008, Looking at the Class Associative Classification Training Algorithm, In Proceedings of the $5^{\text {th }}$ International conference on Information Technology: New Generation, Las Vegas, Nevada April 7-9.

[14] Zaki, M., Parthasarathy, S., Ogihara, M. \& Li, W., 1997, New Algorithms for Fast Discovery of Association Rules, In Proceedings of the 3rd International Conference on Knowledge Discovery and Data Mining, Newport Beach, CA, August 14-17. 